\title{
Escolarización secundaria: asignaturas pendientes y expresiones en materia de inequidades de género*
}

\author{
Ana Miranda** \\ Analía Otero ${ }^{* * *}$
}

\begin{abstract}
Resumen
El texto presenta un análisis sobre las principales actividades de los y las jóvenes en relación a la participación laboral y a las obligaciones extra-escolares, proponiendo una serie de cuestionamientos guiados por la consigna: en qué medida estas actividades pueden afectar la continuidad en la educación secundaria. Se sostiene, como supuesto clave, la vigencia de expresiones de desigualdad donde la condición de género tiene implicancias sustantivas. Hecho que convoca a desentrañar cuanto hay de nuevo y cuanto de continuidad en las tendencias hacia la desigualdad de oportunidad y accesos al bienestar entre las nuevas generaciones.
\end{abstract}

Palabras clave: Juventud, Educación Secundaria, Trayectoria Educativa, Desigualdad, Género.

\footnotetext{
" Recebido para publicação em março de 2010, aceito em maio de 2010.

** Dra. en Ciencias Sociales, FLACSO Sede Académica Argentina. Investigadora del CONICET y Coordinadora del Programa de Investigaciones en Juventud de la Flacso.amiranda@flacso.org.ar

**** Dra. en Ciencias Sociales, FLACSO Sede Académica Argentina. Investigadora del CONICET e Investigadora principal del Programa de Investigaciones en Juventud de la Flacso. aotero@flacso.org.ar
}

cadernos pagu (34), janeiro-junho de 2010:75-106. 


\title{
Escolarización secundaria
}

Secondary Schooling:

Pending Subjects and Expressions Regarding of Gender Inequality

\begin{abstract}
The text introduces an analysis of the main activities of male and female youths in connection with labor involvement and extracurricular duties, by proposing a series of issues guided by the question: to what extent do such activities affect continuity in secondary education. As a key assumption, we point to the prevailing expressions of inequality where gender condition carries far-reaching implications. This fact leads us to find out how much is new and how much is continuity in trends towards inequality of opportunity and access to welfare among new generations.
\end{abstract}

Key Words: Youth, Secondary Education, Educational Development, Inequality, Gender. 
Ana Miranda e Analía Otero

\section{Introducción}

La educación secundaria representa uno de los principales desafíos en materia de política educativa y políticas de juventud en la Argentina contemporánea. Estos desafíos tienen relación con problemáticas de distinto orden, tales como la convivencia escolar, la actualización de los conocimientos en virtud del cambio tecnológico, la pertinencia de la formación, las nuevas culturas juveniles, la mayor retención y terminación de los estudios, sobre todo entre aquellos estudiantes de menores recursos económicos, entre otros.

Las problemáticas de la educación secundaria no son ajenas a procesos de orden general que afectan al conjunto de la sociedad, tanto en Argentina como en el resto de los países latinoamericanos. Las transformaciones económicas, sociales y culturales de fines del siglo veinte tuvieron un amplio impacto en las condiciones de vida de la población, dando cuenta de la aparición de una nueva cuestión social en donde temáticas como la pobreza, la desocupación y la desigualdad cobran un lugar central en el debate público y académico.

En este marco, la integración social de la juventud es una preocupación que se expresa constantemente entre distintos actores sociales; en los medios de comunicación, por ejemplo, a partir del seguimiento de casos policiales protagonizados por menores; entre las autoridades judiciales y algunos sectores del gobierno, en lo que respecta al debate de la responsabilidad penal juvenil (en referencia a la baja de la edad de imputabilidad penal); entre los docentes, respecto a las dificultades frente a casos de "indisciplina" escolar; en el sistema de salud, por los excesos en el consumo de alcohol y las problemáticas ligadas al embarazo temprano o interrumpido de forma clandestina; entre los líderes religiosos, respecto a las denuncias sobre aquellos jóvenes que "no estudian, ni trabajan". Siempre, la preocupación de base es: ¿qué hacemos, qué proponemos a los y las jóvenes? 
Escolarización secundaria

Por otro lado, durante los últimos veinte años, se ha producido un importante avance en relación con los derechos de la juventud. La Convención de los Derechos del Niño, la promoción del enfoque que sostiene a los y las jóvenes como sujetos de derecho (antes que como objeto de tutela), las campañas destinadas a la erradicación del trabajo infantil, la elevación de la edad de obligatoriedad escolar, la promoción de la participación juvenil, entre otras medidas, fueron modificando la percepción sobre los derechos y las necesidades de los jóvenes en la sociedad contemporánea.

En Argentina se aplicaron medidas que marcharon en dirección a estos avances en la elevación consecutiva de los años de obligatoriedad escolar. Una primera modificación se produjo en 1993 con la aprobación de la Ley Federal de Educación $\left(\mathrm{n}^{\circ}\right.$ 24.195), la cual dictaminó un piso de 10 años de obligatoriedad escolar que abarcaba entre los 5 años (el nivel pre-escolar) y los 15 años de edad (finalización de la escolaridad básica). Una segunda transformación se implementó en el año 2006 con la sanción de la Ley de Educación Nacional ( $\mathrm{n}^{\circ}$ 26.206), que elevó los años de escolaridad hasta un total de 13, promoviendo la obligatoriedad de la educación secundaria.

Se puede afirmar sintéticamente, que la obligatoriedad de la educación secundaria se sancionó en el marco de un proceso de avance de los derechos de los y las jóvenes, pero que, al mismo tiempo, se aplicó en el contexto de la nueva cuestión social, y en el marco de una significativa vulnerabilidad social de la juventud. De tal forma que, más allá de las tendencias generales, de los avances en la legislación y de la opinión pública general, día a día quedan afuera de la educación secundaria un gran número de jóvenes, principalmente varones que provienen de hogares de bajos ingresos.

Frente a esta realidad y con el objetivo de realizar un aporte al debate sobre la desigualdad social, en el presente texto se analizan las tendencias en la evolución del acceso al diploma de la educación secundaria entre hombres y mujeres de distintos grupos 
sociales en Argentina ${ }^{1}$, así como también se abordan las principales actividades educativas y laborales de los y las jóvenes con el objetivo de discernir en qué medida la participación en actividades domésticas y laborales pueden afectar la continuidad educativa y el rendimiento escolar.

A lo largo del documento se trabaja con datos de distintas fuentes y estructuras. Por un lado, datos producidos por el Instituto Nacional de Estadísticas y Censos (INDEC), a través de la Encuesta Permanente de Hogares. Por otro, con información primaria obtenida a través de encuestas y entrevistas con estudiantes del ante-último año de la educación secundaria. Al respecto, es preciso señalar que la información bajo análisis fue relevada con cuestionarios que trabajan a partir de distintas lógicas y objetivos, en virtud de lo cual no admiten comparaciones, ni homologaciones.

\section{Evolución en el acceso a la educación secundaria}

La educación secundaria se difundió en Argentina desde mediados del siglo $\mathrm{XIX}^{2}$, su expansión se desarrolló en ofertas

1 El género en cuanto categoría social presenta un interesante debate acerca de las desigualdades entre hombres y mujeres, poniendo en énfasis en la multiplicidad de identidades, las relaciones de poder y los aspectos culturales $e$ históricos que se atribuyen al carácter femenino y masculino en diferentes contextos históricos y sociales (Gamba, 2007). A pesar de la riqueza de esta discusión, en el abordaje cuantitativo se utilizará la variable sexo -que distingue hombres y mujeres en referencia a su nacimiento biológico- en correspondencia con la información estadística disponible.

2 Desde mediados del siglo XIX hasta finales del siglo XX el sistema educativo argentino se organizó de la siguiente manera: la educación primaria de carácter obligatorio abarcaba 7 años que se cursaban en edades teóricas entre los 6 y los 12 años. La educación secundaria se desarrollaba entre 5 y 6 años consecutivamente a la finalización de la educación primaria. La educación secundaria se dictaba en distintas modalidades que se detallan en el cuerpo principal del texto. Este esquema se modificó en la década de noventa con la Ley Federal de Educación, en el marco de un conjunto de medidas de reforma económica y social. 
Escolarización secundaria

post-primarias según distintas modalidades de egreso, que se organizaron en ciclos formativos de 5 o 6 años. Las modalidades fueron: bachiller, normal (formación docente), comercial, $y$ técnica. La evolución de las mismas tuvo diversos momentos, los cuales estuvieron relacionados con las distintas estrategias económicas y políticas en nuestro país (Kaplan, Miranda y Moragues, 2001).

Al respecto, se ha señalado que hasta entrada la década del'30, la educación secundaria estaba muy vinculada a la instrucción de elites en la modalidad de bachiller y la formación docente, siendo hasta ese momento, un nivel abiertamente selectivo, que experimentaba un crecimiento parsimonioso. Durante este período, accedían a la educación secundaria los varones de las clases económicas más acomodadas, como se observa en las primeras columnas del gráfico 1 , en donde quedan reflejadas las tendencias del acceso al diploma secundario entre hombres y mujeres de distintos grupos de edad.

A partir de mediados de los años cuarenta, y en un contexto caracterizado por la industrialización por sustitución de importaciones, se produjo un fuerte incremento del número de alumnos sustentado en la modalidad técnica. Luego, sobre principios de los sesenta, y en vinculación con la cada vez más significativa presencia del sector comercial y de servicios, la expansión de mayor importancia se dio en la modalidad comercial (Gallart, 1984). Es en ese momento, cuando se produjo la equiparación entre hombres y mujeres respecto al acceso del diploma secundario, justamente en la generación que nació entre 1942 y 1951, es decir en la cohorte que hacia el año 2006 contaba con entre 55 y 64 años de edad.

Unos años más tarde, y en el marco de la transición democrática durante los años ochenta, la matrícula de la educación secundaria comenzó a incrementarse sustantivamente sobre todo en las modalidades de bachiller y comercial. En esta dirección, se sostuvo que durante esos años se había producido el inicio del proceso de "masificación" de la educación secundaria 
(Braslavsky y Filmus, 1987). Varios factores asociados a la menor selectividad del nivel contribuyeron en este proceso, por ejemplo la implementación de medidas relativas a la eliminación del examen de ingreso, la modificación y la democratización del sistema de sanciones, así como también, las crecientes dificultades que los y las jóvenes comenzaron a encontrar a la hora de conseguir un empleo, lo cual redundó en la búsqueda de mayores certificaciones educativas (Jacinto, 2006). En este proceso, el diploma de la educación secundaria se fue convirtiendo en una condición necesaria (aunque no suficiente) para el ingreso a un puesto de trabajo en el sector formal de la economía. 
Escolarización secundaria

\section{Gráfico 1}

Porcentaje de población con secundaria completa según sexo y grupos de edad*

Segundo semestre de 2006 - Total de los aglomerados urbanos. ${ }^{3}$

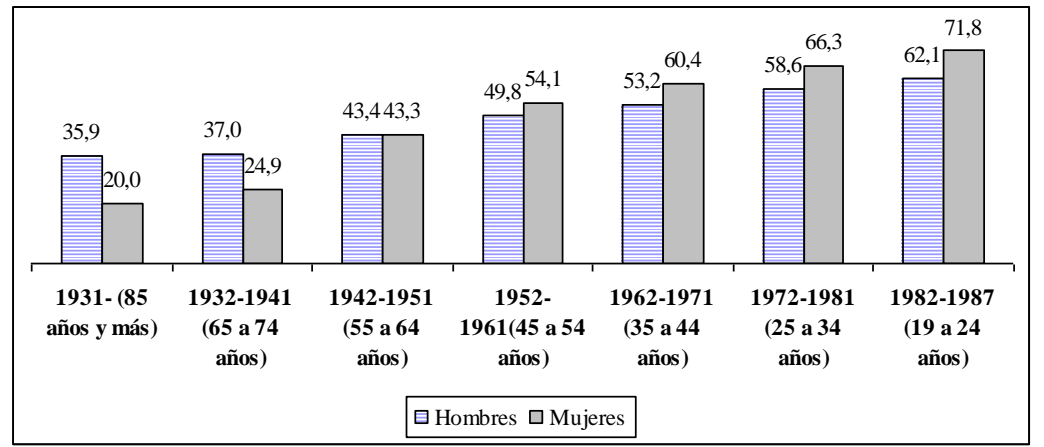

Fuente: Elaboración propia en base a datos de la EPH-INDEC.

* En el gráfico se expresan los porcentajes de población que alcanzaron el diploma de la educación secundaria en cohorte de 10 años. De forma tal que, en la primera columna están representados aquellos hombres y mujeres que nacieron hasta 1931. En la segunda columna, aquellos que nacieron entre 1932 y 1941 , etc.

Una década después, es decir en los noventa y a partir de la modificación prevista por la Ley Federal de Educación, se presenció nuevamente una fuerte incorporación de alumnos, fundamentalmente en aquellos tramos correspondientes con la nueva EGB3 (es decir el tramo que comprendía a los y las jóvenes

3 En el cuadro se trabaja con datos producidos por la EPH-INDEC, para el total de los aglomerados urbanos. Dicha fuente brinda la posibilidad de procesar micro-datos, y de esta forma combinar aspectos educativos y socioeconómicos de hombres y mujeres de distintos grupos de edad. Ahora bien, en la lectura sobre la interpretación de la información debe tomarse en cuenta que sus resultados corresponden con una "foto" de la situación en el período considerado (en este caso: el segundo semestre 2006). Razón por la cual los procesamientos no evidencian la situación de hombres y mujeres en etapas anteriores. Por ejemplo, no muestran la situación educativa en 1940, sino que representan la situación de la generación que habita en nuestro país en la actualidad y nació en 1940. 
entre los 12 y los 15 años de edad), siguiendo así constante la preponderancia de las orientaciones vinculadas a las humanidades, las ciencias sociales y la comercialización, por sobre las orientaciones asociadas a la educación técnica o las ciencias exactas y naturales, preponderancia que continúa hasta la actualidad a pesar de los esfuerzos gubernamentales. ${ }^{4}$ Paralelamente, las problemáticas relativas a la desocupación y a la calidad de los empleos a los que los y las jóvenes pueden acceder siguieron vigentes, inclusive frente al amplio crecimiento económico que se inició a partir del año 2003.

En este marco y como se ha señalado en la introducción, en el año 2006 la Ley de Educación Nacional dictaminó la obligatoriedad de la educación secundaria. A partir de la sanción de esta norma, el Estado deberá ir desarrollando las estrategias necesarias para que todos los y las jóvenes puedan acceder al diploma de dicho nivel. Y, como puede observarse en el gráfico 2, como parte de los desafíos pendientes, las principales acciones deberán estar destinadas a la retención de los y las jóvenes (sobre todo hombres) que pertenecen a los grupos sociales con menores recursos económicos.

\footnotetext{
4 A partir de la sanción de la Ley Federal de Educación (1993) se produjo una modificación en la organización del sistema educativo. El esquema de ciclos y niveles se organizó a partir de una Educación General Básica (EGB) de 9 grados/años que, junto con la educación preescolar, se convirtieron en obligatorios (lo que hace un total de 10 años de escolaridad obligatoria), y el Polimodal de 3 años de extensión. De tal forma que la educación secundaria quedó -en algunos casos- dividida en dos ciclos con lógicas educativas diferentes: la EGB3 (último tramo de la EGB) y el Polimodal. Las antiguas modalidades se organizaron a partir de cinco orientaciones del Polimodal: a) Producción de Bienes y Servicios, b) Economía y Gestión de las Organizaciones, c) Humanidades y Ciencias Sociales, d) Ciencias Naturales y e) Comunicación, Arte y Diseño.
} 
Escolarización secundaria

\section{Gráfico 2}

Jóvenes entre 19 y 24 años de edad con secundaria completa según nivel socioeconómico y sexo

Segundo semestre de 2006 - Total de los aglomerados urbanos

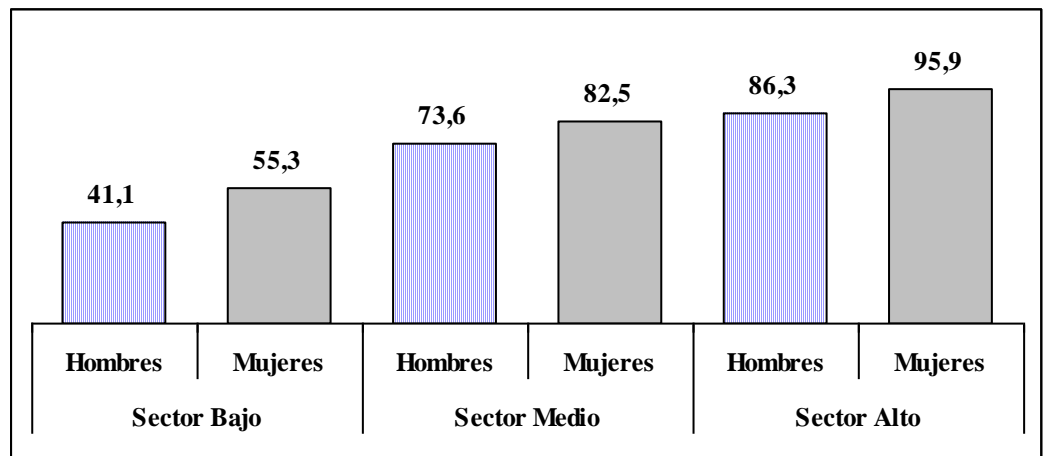

Fuente: Elaboración propia en base a datos de la EPH-INDEC.

\section{Principales actividades de los y las jóvenes}

A pesar de los avances en materia educativa en relación al acceso al diploma de la educación secundaria, existe aún una brecha pronunciada entre los y las jóvenes que habitan en hogares de menores ingresos y aquellos de hogares de ingresos altos. En esta dirección, estudios de campo han argumentado que el abandono de la educación secundaria forma parte de un proceso que combina aspectos vinculados al ámbito educativo, con oportunidades laborales, eventos inesperados a nivel personal (la pérdida del trabajo de alguno de los padres, accidentes u otros eventos) y necesidades económicas (Binstock y Cerrutti, 2005). En lo que sigue de este apartado, con el objetivo de abordar la situación social de los y las jóvenes actuales, se presenta un análisis donde se expresan distintas formas de inserción social juvenil a partir de la combinación entre actividades educativas y laborales. ${ }^{5}$

5 Si bien las actividades educativas y laborales no agotan las necesidades y
deseos de los jóvenes en cuanto al uso de su tiempo vital, los datos con los cuales 
Gráfico 3

Principales actividades de los y las jóvenes de 15 a 18 años Segundo semestre de 2006 - Total de los aglomerados urbanos

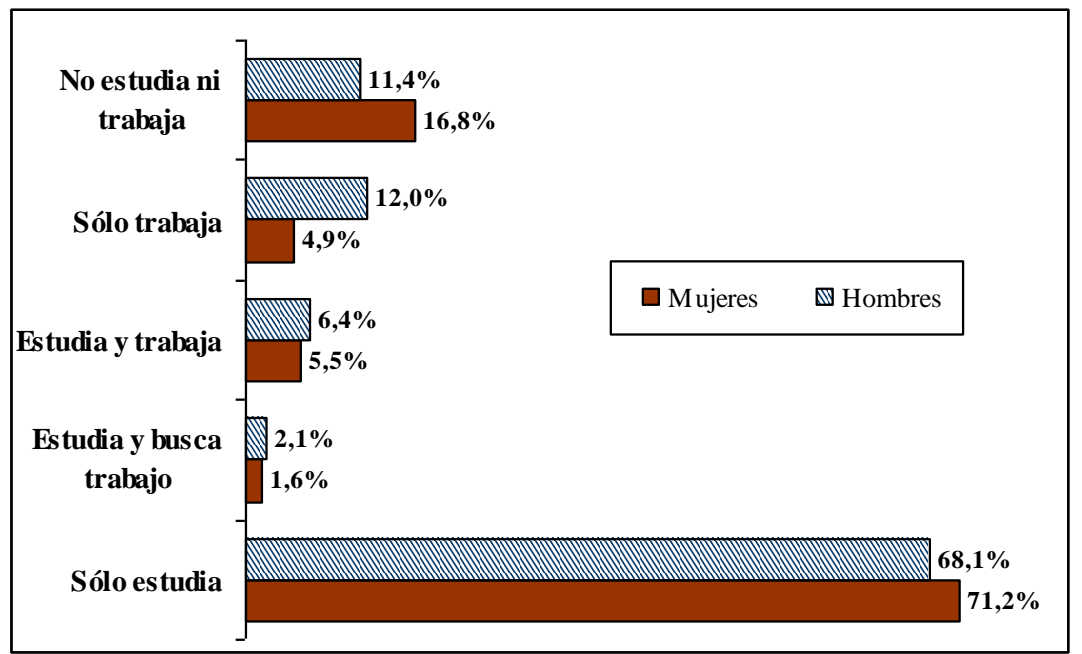

Fuente: Elaboración propia con datos de la EPH-INDEC.

* En la categoría "no estudia ni trabaja" se sumaron los valores de los y las jóvenes que son "inactivos y no estudian" y los que son "desocupados y no estudian".

Entre los resultados que se detallan en el gráfico 3, se puede observar una fuerte tendencia hacia la escolaridad como actividad principal entre los jóvenes en edad teórica de asistir a la educación secundaria. No obstante, en el mismo gráfico se hace evidente la persistencia de estudiantes que trabajan, de jóvenes que trabajan y no asisten a la educación secundaria, y de jóvenes que no estudian ni trabajan. De modo que, prácticamente 3 de cada 10 jóvenes desarrollan tareas que los distancian de la escolaridad

estamos trabajando sólo nos permiten acercarnos a la dinámica de la inserción laboral a partir de dichas actividades. En esta dirección, desde el Programa de Investigaciones de Juventud, hemos promocionado la realización de encuestas de juventud, las cuales presentan un abordaje integral sobre los jóvenes y sus condiciones de vida. 
Escolarización secundaria

como actividad principal. Algunos combinan la educación con el trabajo. Otros únicamente desempeñan una actividad laboral. Y otra parte ha abandonado la actividad educativa y no participa del mercado de trabajo. Todos ellos se encuentran en un terreno de vulnerabilidad. Terreno en el cual las diferencias en cuanto al sexo son significativas. Mientras las mujeres que no asisten a la educación tienden a permanecer inactivas vinculándose de manera temprana a las actividades domésticas familiares, los hombres participan de manera más temprana en actividades laborales.

\section{Ocupaciones extra-escolares}

En base al seguimiento de la educación y el empleo entre jóvenes en edad teórica de asistir a la educación secundaria, desarrollamos un ejercicio que contempló el vínculo con el mundo laboral de estudiantes que asistían al ante - último año de dicho nivel educativo. Es interesante advertir aquí que en investigaciones anteriores nos focalizamos en la inserción laboral de los egresados $^{6}$, en cambio, en esta oportunidad, nos planteamos un abordaje diferente, con el objetivo de analizar cómo el mundo del trabajo se "metía" en el ámbito escolar, a través de la participación de los estudiantes en actividades laborales o domésticas. Tras ese objetivo, se trabajó con información relevada entre estudiantes ${ }^{7}$, mediante un cuestionario en el cual se consultó detenidamente sobre las actividades que los encuestados

\footnotetext{
6 Entre 1998 y 2003 desarrollamos la investigación "La inserción ocupacional de los egresados de la escuela media", la cual tuvo una amplia repercusión en el ámbito educativo nacional.

7 Proyecto "Intersecciones entre desigualdad y educación media: un análisis de las dinámicas de producción y reproducción de la desigualdad escolar y social en cuatro jurisdicciones", que se desarrolló bajo la dirección de Inés Dussel, en conjunto con la dirección de Investigación de la Secretaría de Educación de la Ciudad de Buenos Aires, la Univ. Nac. de Salta, la Univ. Nac. de La Plata y la Univ. Nac. del Comahue.
} 
afirmaban realizar por fuera del horario escolar, ya sean en tareas laborales o domésticas.

Los primeros resultados obtenidos pusieron en evidencia que - en términos generales - la mayoría de los estudiantes desarrollaban alguna actividad extra-escolar. Nos pareció convincente suponer que dichas respuestas escondían situaciones muy dispares en cuanto al grado de responsabilidad y el tiempo destinado a las tareas. Entonces, en dirección a profundizar el análisis, se introdujo una nueva variable que incorporó la dimensión de la "intensidad horaria", a partir de la cual se elaboró un agrupamiento que distinguió cinco categorías, cuya descripción se presenta a continuación:

1) Actividad laboral intensa: presenta la situación de aquellos estudiantes que trabajan o ayudan en trabajos de algún familiar en forma habitual (todos los días).

2) Actividad laboral moderada: da cuenta de la situación de estudiantes que algunas veces trabajan o ayudan en trabajos de algún familiar.

3) Actividad doméstica intensa: se trata de estudiantes que ayudan en tareas domésticas (cuidar a los hermanos menores, limpiar la casa, hacer las compras) en forma habitual.

4) Actividad doméstica moderada: refiere a la situación de aquellos estudiantes que ayudan algunas veces en tareas domésticas.

5) Sin ocupaciones laborales y/o domésticas: presenta a aquellos estudiantes que no ayudan en las tareas domésticas/laborales o lo hacen esporádicamente.

Los resultados del proceso se exponen en el gráfico 4, donde aparecen representadas las diferencias en cuanto a las cargas extra-escolares entre jóvenes de distintos sectores sociales. Los estudiantes de sectores bajos tienen mayor responsabilidad en las tareas extra-escolares que los estudiantes de sectores medios y altos. Estos últimos -antagónicamente a los anteriores -, parecen 
Escolarización secundaria

estar liberados de las tareas vinculadas a actividades domésticas y/o laborales.

Al mismo tiempo, son notables los contrastes entre hombres y mujeres. Es decir que aquí se verifica también la significativa influencia de la variable sexo. En primer lugar, las mujeres de todos los sectores sociales manifestaron realizar actividades domésticas - prácticamente - en la misma proporción. Pero, a la hora de medir la intensidad se comprobaron fuertes disparidades entre aquellas jóvenes que habitan en hogares de ingresos bajos (39,2\% con actividad doméstica intensa), contraste que está fuertemente asociado al papel diferencial de las mujeres al interior de la estrategia reproductiva familiar en los distintos grupos sociales (Gallart, 1992).

\section{Gráfico 4}

Ocupaciones extra-escolares de los estudiantes secundarios según sector social

Ciudad de Buenos Aires, Partidos del Conurbano, Neuquén y Salta

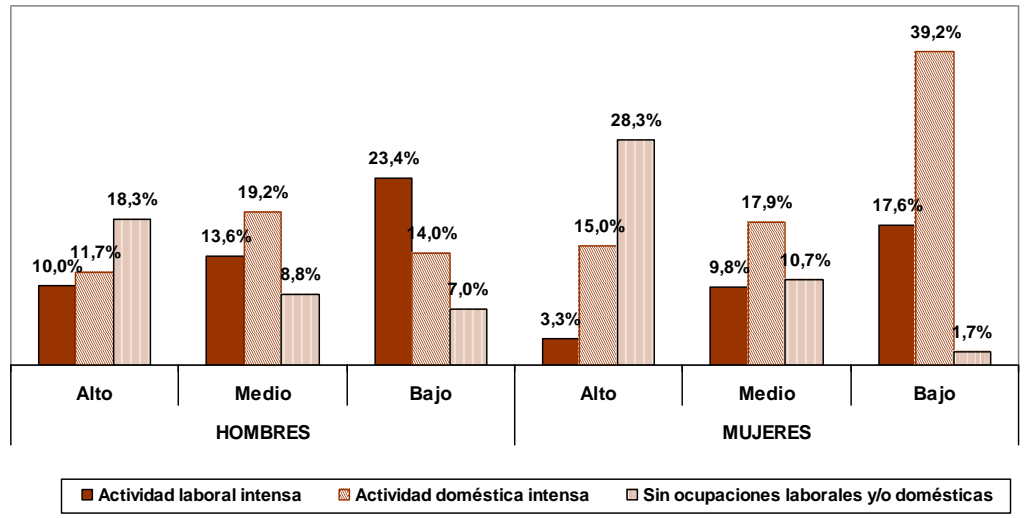

Fuente: Elaboración propia, encuesta alumnos de la investigación: "Intersecciones entre desigualdad y escuela media. Un análisis de las dinámicas de producción y reproducción de la desigualdad escolar y social en cuatro jurisdicciones", 2005-2008. 
En segundo lugar, la dedicación a actividades domésticas es de menor proporción entre los hombres, así como su intensidad es descendente según los grupos sociales (más baja entre los altos, más alta entre los bajos) y en ningún caso supera al $20 \%$ (sector medio). En sentido inverso, la participación laboral entre los hombres sigue la lógica de la estructura social 38,3, 52,0 y 67,3\% en los sectores alto, medio y bajo respectivamente, siendo mucho más intensa entre los hombres de este último sector social.

En tercer lugar, entre las mujeres la participación en actividades laborales, si bien levemente menor, es también incremental según se desciende en la estructura social. Destacándose la amplia proporción de muchachas del sector alto sin ocupaciones laborales y domésticas (28,3\%), y la amplia participación de muchachas de sectores bajos en tareas que son centrales para la reproducción de la estructura familiar $(49,4 \%)$. Es en esta distancia entre las actividades de las mujeres de distintos grupos sociales en donde la dinámica de la desigualdad parece plasmarse de modo más evidente.

Además, a partir del ejercicio propuesto avanzamos en el proceso de investigación, destacando la influencia de las actividades extra-escolares en relación a las trayectorias educativas de los estudiantes. A partir del análisis, diseñamos una síntesis combinatoria entre ocupaciones extra-escolares $e$ indicadores de rendimiento escolar. Para este ejercicio establecimos dos categorías:

1) Trayectoria sin sobresalto: son aquellos estudiantes que no repitieron o reprobaron más de 5 materias.

2) Trayectoria con sobresalto: son aquellos que repitieron y/o reprobaron más de 5 materias, en alguno de los años de estudio. 
Escolarización secundaria

Cuadro no 1

Ocupaciones extra-escolares y trayectoria educativa de los estudiantes

\begin{tabular}{|c|c|c|c|c|c|c|}
\hline \multirow{2}{*}{$\begin{array}{l}\text { Trayectoria } \\
\text { educacional }\end{array}$} & \multicolumn{5}{|c|}{ Ocupaciones extra escolares } & \multirow[b]{2}{*}{ Total } \\
\hline & $\begin{array}{c}\text { Actividad } \\
\text { laboral } \\
\text { intensa }\end{array}$ & $\begin{array}{c}\text { Actividad } \\
\text { laboral } \\
\text { moderada }\end{array}$ & $\begin{array}{c}\text { Actividad } \\
\text { doméstica } \\
\text { intensa }\end{array}$ & $\begin{array}{l}\text { Actividad } \\
\text { doméstica } \\
\text { moderada }\end{array}$ & $\begin{array}{c}\text { Sin } \\
\text { ocupaciones } \\
\text { laborales } \\
\text { y/o } \\
\text { domésticas }\end{array}$ & \\
\hline $\begin{array}{c}\text { Con } \\
\text { sobresalto }\end{array}$ & $43,0 \%$ & $40,1 \%$ & $29,4 \%$ & $21,6 \%$ & $14,0 \%$ & $32,1 \%$ \\
\hline
\end{tabular}

Fuente: Elaboración propia, encuesta alumnos de la investigación:

"Intersecciones entre desigualdad y escuela media. Un análisis de las dinámicas de producción y reproducción de la desigualdad escolar y social en cuatro jurisdicciones", 2005-2007.

Como síntesis del trabajo, observamos que son los estudiantes que realizan actividades laborales más intensas los que registran altos porcentajes de repitencia. Esta relación dista de ser lineal ya que casi un $60 \%$ de los estudiantes que desarrollan alguna actividad de manera intensa y/o moderada no sólo no repitieron, sino que tampoco reprobaron más de 5 materias. Posteriormente, en función de analizar con mayor profundidad las características de esta relación "no lineal", retomamos el mismo ejercicio tomando en cuenta la variable de sector social. Considerando esta nueva variante, se presentan dos situaciones extremas: a) Aquellos que realizan una actividad laboral intensa, b) Quienes no realizan ninguna actividad extra-escolar. 
Gráfico no 5

Trayectoria educacional y actividad laboral intensa según sector social de la escuela

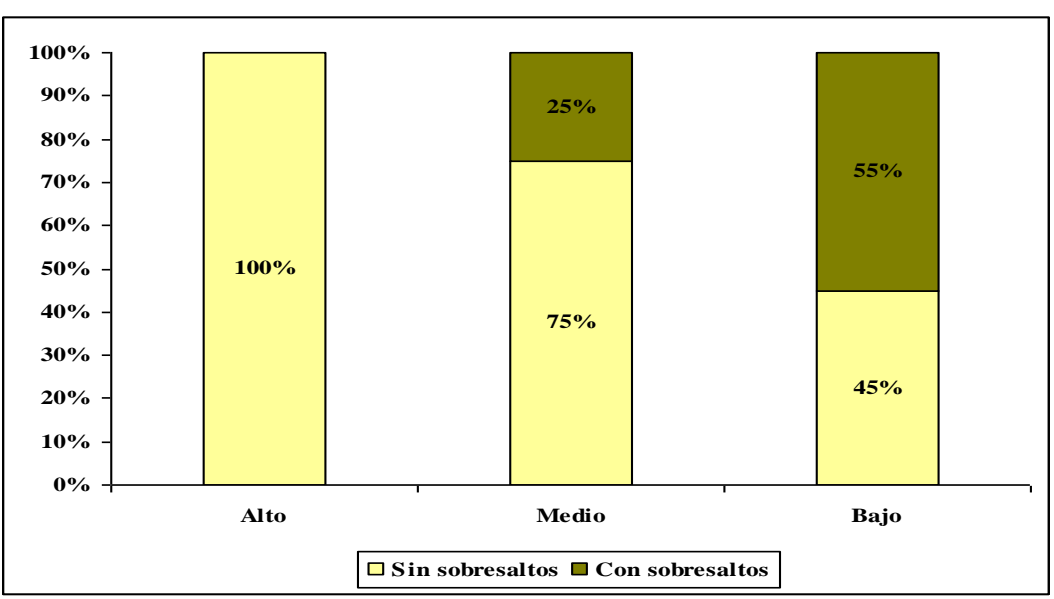

Fuente: Elaboración propia, encuesta alumnos de la investigación: "Intersecciones entre desigualdad y escuela media. Un análisis de las dinámicas de producción y reproducción de la desigualdad escolar y social en cuatro jurisdicciones", 2005-2007.

Finalmente, un punto destacado al que arribamos mediante el ejercicio - que se puede verificar en los gráficos $n^{\circ} 5$ y n ${ }^{\circ} 6$ - es que la incidencia de las actividades extra-escolares en las trayectorias educativas parece estar fuertemente mediada por el sector social de los alumnos. Lo que comprueba el hecho de que sólo entre los estudiantes del sector social bajo y medio que realizan actividades laborales intensas se presentan trayectorias educativas con sobresaltos, $\mathrm{y}$, entre aquellos que provienen de grupos sociales de alto poder adquisitivo no se encuentran sobresaltos, siquiera en aquellos que manifiestan tener una actividad extra-escolar intensa. 
Escolarización secundaria

Gráfico no 6

Trayectoria educacional sin ocupaciones laborales $y / 0$ domésticas según sector social de la escuela

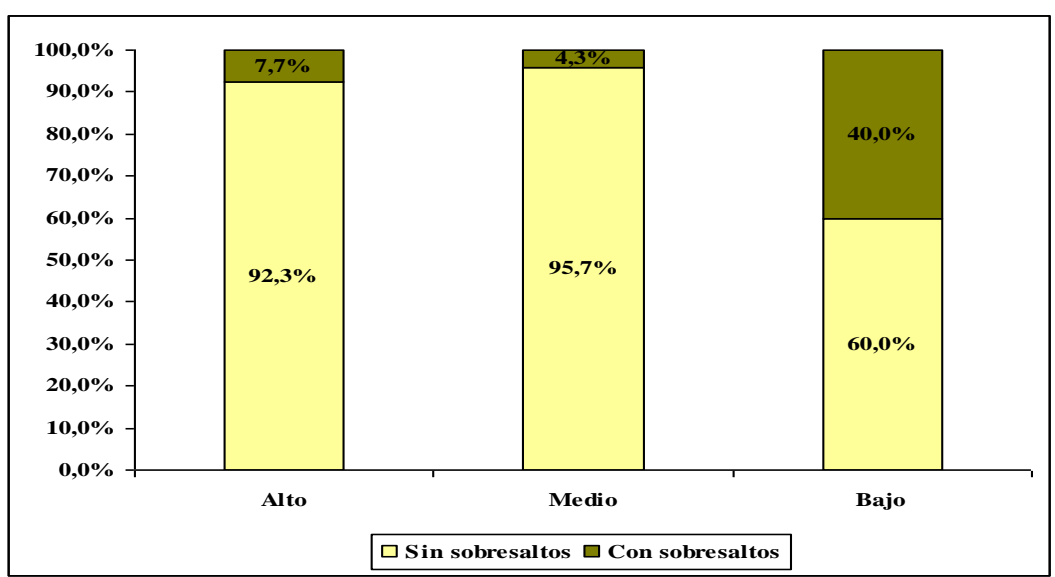

Fuente: Elaboración propia, encuesta alumnos de la investigación: "Intersecciones entre desigualdad y escuela media. Un análisis de las dinámicas de producción y reproducción de la desigualdad escolar y social en cuatro jurisdicciones", 2005-2007.

Estas afirmaciones corroboran entonces una primera desigualdad social y educativa, entre los y las jóvenes de distintos sectores sociales. Más aún, entre los estudiantes del sector social bajo que están exentos de actividades laborales y domésticas, pues el $40 \%$ presenta trayectorias con sobresalto (gráfico 6). Por otro lado, mientras que la actividad laboral intensa no parece afectar la escolaridad en los estudiantes de sectores altos, las ocupaciones extra-escolares sí parecen hacerlo en los estudiantes de sectores medios. 
Ana Miranda e Analía Otero

Lo extra-escolar, un camino y sus complejidades

En el apartado anterior se analizaron las principales tendencias en las ocupaciones extra-escolares de los alumnos de los últimos años de la educación secundaria, a partir de un ejercicio que delimitó distintas intensidades y estableció sus posibles efectos en las trayectorias escolares que van trazando. Dando continuidad al trabajo, interesa ahora profundizar la exploración a través del análisis de información cualitativa; más específicamente en base a testimonios que retoman e ilustran los ítems enunciados.

Partiendo del supuesto de que las articulaciones entre la educación y el trabajo resultan complejas y cambiantes, y que pueden, por ejemplo, acarrear resultados diferentes o contrarios a los esperados (De Ibarrola, 2004); se trabajó con la idea de profundizar en las complejidades actuales del vínculo educacióntrabajo entre hombres y mujeres de distintos grupos sociales, captando situaciones bien diferenciales entre los mismos.

Los insumos analizados fueron relevados a través de la aplicación de entrevistas semi-estructuradas durante el trabajo de campo desarrollado durante el 2006. La guía de entrevistas contemplaba un conjunto de temáticas que interrogaban, entre otras, la situación actual de los y las jóvenes, las experiencias laborales y educativas, así como también en sus opiniones y perspectivas respecto al futuro. En este marco, se presenta una selección que fue elaborada a partir del estudio de expresiones de aquellos estudiantes que manifestaron desarrollar alguna ocupación laboral o actividad extra-escolar dentro o fuera del hogar.

Siguiendo hilaciones sobre las dinámicas y las desigualdades, los relatos se organizaron en torno a dos ejes. El primero aborda las variaciones contextuales, tomando en cuenta el sexo y el sector social de la escuela de donde provienen de los entrevistados. Por su parte, el segundo eje presenta las miradas 
Escolarización secundaria

sobre el trabajo. Este último está destinado a destacar la influencia del trabajo durante la etapa escolar secundaria y abordar aspectos sobre como piensan estos jóvenes el futuro. Resta aclarar que la pertinencia sobre la reflexión de ambos ejes permanece estrechamente asociada a los efectos que pueden acarrear en la biografía de los y las jóvenes.

\section{Distintas responsabilidades, distintos empleos}

En primer término, es interesante plantear - aún sin inferir generalidades -, que en el trabajo de campo, en las escuelas, nos encontramos con jóvenes estudiantes que afirmaban ocupar buena parte de su tiempo cotidiano ejerciendo tareas extraescolares. En segundo lugar, es importante observar que en los casos entrevistados el trabajo se asume como una actividad que requiere "responsabilidad". No obstante, las condiciones en las que se desarrollan las actividades imprimen rasgos heterogéneos entre las experiencias. Lo sustantivo, aquí, ha sido hacer hincapié en una cuestión bien interesante: aún cuando los y las jóvenes realicen ocupaciones similares, por ejemplo, los trabajos presentan rasgos comunes en tanto informales y eventuales; el contexto marca contornos que difieren sustantivamente.

Asimismo, las experiencias laborales son disímiles según la intensidad y el grado de responsabilidad en que los y las estudiantes se vean implicados. En este marco, los relatos que siguen trazan vivencias dispares entre sí, aunque en todos los casos se denota que las mismas se encuentran inscriptas o vinculadas al entorno familiar. Se hallaron casos en los cuales la ocupación actual no constituye su primera experiencia laboral. En este sentido, es entre los estudiantes varones del sector social bajo donde la trama discursiva indica el inicio de trayectorias laborales a temprana edad. Otro relato presenta la coexistencia de varios trabajos, dado los escasos ingresos de cada uno de ellos. De esta forma se encuentra un paliativo a través del cual sumando actividades se intentan costear básicamente los gastos personales. 
Un aspecto distintivo en las ocupaciones frecuentes entre varones y mujeres es que aún aquellas que logran incursionar en el ámbito laboral tienden a desarrollar tareas vinculadas al rubro textil. Varios ejemplos de las alumnas entrevistadas dan cuenta de ello. La producción textil parecer absorber buena parte de las "jóvenes estudiantes/ocupadas".

(...) laburaba en la pizzería de delivery, estuve 2 años y medio, hace, desde pibe, yo tengo 17, a los 14 salía con mis amigos así a la casa de mi amigo, el padre era fletero y salíamos a hacer changas con el padre, nos pagaba, desde chico que me gusta laburar, siempre dije que quería salir a laburar y tener mi plata y ahora se dio la posibilidad del laburo este y estoy bien, estoy tranquilo. (...) vamos a kioscos, mi tío nos dio una dirección, es proveedor de $\mathrm{xx}$ [nombra una empresa tabacalera líder] mi tío contrató una camioneta, nos dio la camioneta a nosotros, salimos a laburar, nos pagan $1 \$$ por metro cuadrado, no, $2 \$(\ldots)$ (Varón, 17 años, Escuela Pública, Modalidad Comercial, Sector Social Bajo, Ciudad Autónoma de Buenos Aires).

- (...) tiño chalinas con mi tía y mi tía abuela, las vendo, pero en realidad me lleva mucho más tiempo de lo que gano y etc., es bastante diferente lo que gano de lo que me cuesta hacerlas, no me rinde, pero sí, la verdad sobre todo cuando es necesario que trabajes te cuesta porque yo tengo 17 años, no terminé el secundario, no debería estar trabajando pero gasto $15 \$$ de apuntes por semana, $15 \$$ de apuntes por semana y eso que yo todavía no me tengo que comprar libros 2 o 3 por año, entonces la verdad teniendo17 años..(...) yo doy clases particulares de francés a un chico que viene acá al turno mañana (Mujer, 17 años, Escuela Pública, Modalidad Bachiller, Sector Social Medio, Ciudad Autónoma de Buenos Aires).

Ahora bien, aún cuando de alguna forma los trabajos estén conectados al ámbito familiar, no todos ellos implican una experiencia reconocida como un aprendizaje significativo, 


\section{Escolarización secundaria}

pensando en las trayectorias laborales que pretenden desempeñar a futuro. Sin embargo, el fragmento a continuación - de un joven del sector alto -, presenta un contrapunto interesante con los restantes. Suma mayores condiciones de flexibilidad horaria, y posibilidades de suspender la actividad laboral para la dedicación exclusiva a lo educativo; tanto en relación al término de la escuela secundaria como en función de la elección de una carrera universitaria y una actividad profesional que sea acorde con sus gustos y decisiones. Aquí, se entreve que la familia está ligada a los espacios laborales y las vinculaciones de inserción ocupacional, y también resulta un referente sustantivo en relación a como piensa su camino a futuro.

- (...) este año abandone la parte del trabajo. Porque en el último año o sea se me juntaron varias cosas, un último año de secundaria, que en este caso, es complicada en el hecho de que tenés una carga horaria muy fuerte, y es una, realmente, es una preparación, para entrar a la universidad. Después, el hecho de elegir carrera (...)

- ¿Contame un poquito como es tu trabajo?

-Mi trabajo. Bueno, como ya te dije yo soy camarógrafo en un programa de televisión. Así que, es un trabajo bastante ameno. Como trabajo con mis...la parte económica, digamos, que es una negociación constante, porque yo trabajo con mis padres, entonces por ahí en un momento me pagaban un sueldo después me lo dejaron de pagar, después arreglamos por otras partes (...)

-¿Y tenías pautado horarios de trabajo?

- (...)Digamos, es un trabajo ameno, bastante exhaustivo porque parecen dos o tres días dos o tres horas, pero son dos o tres horas que tenés que estar todo el tiempo pendiente grabando chequeando, controlando, repitiendo imágenes o haciendo lo que fuere. Pero tiene eso, que no tiene tiempos esquemáticos, que para mi es bárbaro. Y que es otra cosa que estoy pensando yo, a la hora de proyectarme en un futuro. También una actividad que no me involucre, esto ya es muy personal mío, pero que no me 
involucre una rutina (Varón, 17 años, Escuela Privada, Modalidad Bachiller, Sector Social Alto, Neuquén).

Por otra parte, la brecha de condiciones diferenciales se acentúa con agudeza si tomamos en cuenta la variable sexo, un conjunto de rasgos demarcan con claridad que el desempeño de actividades domésticas afecta mayormente la cotidianeidad de las estudiantes que afirman ejercer actividades extra-escolares. Dato que evidencia los sesgos que produce la asociación de las "mujeres" con determinas tareas vinculadas con las tareas propias del ámbito doméstico y/o el cuidado de los niños, etc. Visiones que traducen representaciones históricas respecto a las asignaciones de las mujeres y varones en nuestras sociedades, conductas que traducen "patrones tradicionales de género".

Este hecho da cuenta que - material y simbólicamente -, aún persiste una tendencia a la reproducción de roles propios del interior del núcleo familiar. La dinámica de este mecanismo orienta y circunscribe la tarea de las jóvenes. No obstante una referencia significativa es que esta situación afecta aún más a las jóvenes provenientes del sector social bajo. La visibilización de estas condiciones tan desiguales sobre el modo y el contexto en que se producen tanto las inserciones ocupacionales como el desempeño de las tareas domésticas permiten relevar inequidades en las condiciones bajo las cuales se desempeñan las tareas.

(...) yo estoy trabajando ahora, pero yo me ocupo todos los jueves de cuidar a mi primita, que tiene cuatro años, eso para mi es un trabajo. Yo sé que no es un trabajo, pero para mi demanda una obligación, demanda el jueves dejar cosas que tengo que hacer (...) Pero un trabajo en realidad no es eso,... un trabajo implica ya tener responsabilidad. (...) Son todos los jueves, y varia, llego 13.15-13.30 y me voy 19.30-19 hs.

- ¿Y que recibís a cambio de ese cuidado?

- Bueno, primero pasar el tiempo con Juanita que me re divierto, aprendo muchas cosas porque la verdad que yo 
Escolarización secundaria

no tengo muy buen vínculo con los chiquititos, (...) y además mi tío me paga... (Mujer, 17 años, Escuela Privada, Modalidad Comercial, Sector Social Alto, Ciudad Autónoma de Buenos Aires).

Mi hermana, mi hermana es madre soltera, tiene 23 años eh, tiene dos chicos, uno de 2 años y el otro de 1 año, de lo cual ella está estudiando ahora (...) pero también tiene que trabajar a la tarde, y uno tiene que encargarse de... que sé yo, de limpiar la casa, cocinar y... ehhh de cuidar a mis sobrinos, aparte.

- ¿Qué quiere decir trabajar?

- Es una responsabilidad un trabajo, para mí.

- ¿Por qué?

- Porque... tenés que cumplir con horarios, con exigencias, ehh puntualidad y... después tenés que arreglar el manejo de la plata, que sé yo, por ahí, en algunos lados te hacen trabajar varias horas como en un taller, yo trabajé en un taller, trabajé un mes, o no me acuerdo si tres semanas habrá sido...

- ¿Un taller de qué?

- De costura. Trabajé de ayudante, eh... te pagaban $\$ 10$ el día y trabajabas todo el día entero, trabajabas... te levantabas... a la 7 , entrabas a la 8 , salías a la 1 , entrabas a las 2 y volvías a entrar... y salías a eso de las 10,9 o 10 salías más o menos. Hay días que... porque estaban sobrecargados con los días y tenían que entregar pedidos, te hacían trabajar hasta los fines de semana de corrido, sin dormir. (Mujer, 17 años, Escuela Pública, Modalidad Bachiller, Sector Social Bajo, La Plata).

\section{Ser estudiante, ser trabajador}

En lo que respecta al trabajo - como una de las principales actividades bajo análisis - una de las cuestiones destacadas por el conjunto de los estudiantes se refiere a la carga horaria que requiere el espacio laboral. Es decir, que los y las jóvenes reconocen que la actividad laboral altera el ritmo cotidiano de la 
realización de las tareas escolares; razón por la cual la combinación entre estudiar y trabajar resulta compleja de sostener.

El hecho de compartimentar el tiempo diario entre el estudio y un trabajo resulta una cuestión que acarrea dificultades. Por ello hay relatos en que dichas situaciones son reconocidas como una encrucijada sin muchas alternativas posibles para quienes necesitan contar con un ingreso propio. No obstante, lidiando con estas complicaciones entre los ocupados, los aspectos que aprecian de sus trabajos, así como las razones por las cuales lo hacen también cobran diferentes sentidos. Aquí el panorama exhibe múltiples variaciones. Por ejemplo, en ciertos casos la motivación del trabajo actual se expresa básicamente en función de la remuneración, y de allí las posibilidades económicas para satisfacer consumos personales. No obstante, para otro joven la experiencia laboral en sí misma, aunque de escasa duración por su carga horaria, marchaba en correspondencia con el rubro de interés en actividades futuras. El trabajo parece presentarse allí como un puente para incursionar desde hoy en la elección sobre inserciones estudiantiles por hacer.

¿¿Vos trabajas ahora, digamos...?

- $\mathrm{Si}$, cuando no estoy en la escuela

- ¿Haciendo instalaciones?

- Cuando... mi hermano es... como es el que sabe más, él me asesora, él agarra y él me lleva y... y "vamos a hacer esto y esto y yo te voy a ir orientando".

- Ahhha... ¿qué significa para vos trabajar?

- No sé, yo digo que ehhh... el trabajo para mi es ehhh... es el que me brinda lo que tengo que comer todos los días... (...) la plata que cobro no, no la... no la desprecio así nomás, la guardo, yo sé que a mi me ha costado y... trato de asegurarme de que no la gaste así nomás.

- ¿A vos te afecta un poco esto de que vos trabajas y estudias? 
Escolarización secundaria

- Y algunas veces si porque no me da el tiempo para estudiar porque trabajar a la mañana, venir a la escuela a la tarde y llego a mi casa ya un poco cansado y ya te tirás a dormir (Varón, 19 años, Escuela Pública, Modalidad Comercial, Sector Social Bajo, Salta).

- ¿Y problemas de la gente que está trabajando?

- Bueno... yo estuve trabajando un tiempo y el horario era muy complicado ahí en mi trabajo. Llegaba tipo cuatro de la tarde, salía a las diez y el horario se me recomplicaba. Eso es el tema de los chicos que trabajan y estudian, se me complica con el tema del trabajo, el estudio, el tema de la plata, bueno, y no cobran mucho y tienen que seguir trabajando por razones personales tienen que trabajar si o si, para mantener la familia, pero... como que la plata que obtienen no satisface sus necesidades y tienen que trabajar el doble. Para mí esos temas son los principales para los trabajadores.

- Trabajaba para una empresa de turismo, como promotor, (...) en la calle. Entraba a las cuatro de la tarde y salía a las diez de la noche, y se me complicaba porque del colegio (...) No tenía tiempo a la noche ni para estudiar, así que tuve que dejar.

- ¿Qué pensás hacer cuando termines la secundaria?

- Pienso estudiar turismo, si estudio acá serán cinco años (...) (Varón, 17 años, Escuela Privada, Modalidad Comercial, Sector Social Medio, Neuquén).

Hasta aquí los relatos versaban por cuestiones propias de los espacios laborales y ocupaciones extra-escolares en relación a la combinación con las pautas del sistema educativo. Estimando las opiniones de estos estudiantes respecto al futuro de sus coetáneos, se han seleccionado fragmentos que por su crudeza resultan en verdaderas imágenes crudas en relación a las posibilidades de alcanzar condiciones de bienestar y vida saludable. Un primer motivo señalado es la percepción del aumento de jóvenes sumidos en el camino de la drogadicción para los cuales el futuro parece ceñirse en la imposibilidad total de continuar con sus vidas. Un 
segundo factor vinculado a este último es la figura de los jóvenes como delincuentes.

-¿Qué pensás vos acerca del futuro? ¿Cómo ves el futuro? - ... hoy en día lo que se ve mucho que hay muchos chicos que aumentan la delincuencia, muchos chicos que entran en la drogadicción y que se está generando poco la conciencia de la responsabilidad de los jóvenes más que nada... (Varón, 17 años, Escuela Privada, Modalidad Técnica, Sector Social Medio, Neuquén).

-¿Cómo ves el futuro de los chicos de tu barrio?, más en particular.

- Ya está, hay algunos que ya no tienen futuro, yo no les veo futuro, hay un montón que se drogan, que roban... yo personalmente, para mí no tienen futuro, ya lo perdieron y hay un montón que escuchás que se suicidaron o que los mataron o que entró en cana (Mujer, 17 años, Escuela Pública, Modalidad Comercial, Sector Social Bajo, Ciudad Autónoma de Buenos Aires).

En síntesis, indagando acerca de las opiniones de estudiantes que actualmente trabajan, encontramos una vasta diversidad. Los relatos describen experiencias dispares entre sí, donde el contexto social en el que se enmarcan tiene fuerte influencia. Ciertos aspectos de las condiciones del trabajo como la flexibilidad horaria, la cantidad de horas, la propia tarea que realizan y el pago que reciben, hacen a estas diferencias. De acuerdo a las descripciones, las experiencias remiten a trabajos informales; de escasa duración.

Mediante la exposición se advierten fragmentos que dan cuenta de una distribución dispar de las tareas extra-escolares entre hombres y mujeres. Dicha distribución manifiesta la vigencia de representaciones sociales históricas sobre cada sexo, en nuestra sociedad. Se subraya que entre los varones resulta más corriente la inserción en ámbitos laborales y entre las mujeres el desarrollo de tareas ligadas al ámbito doméstico. Al mismo tiempo, aun entre 
Escolarización secundaria

las mujeres que se desempeñan en actividades extra-escolares pueden coexistir características y sesgos que otorgan un matiz diferente a cada caso.

Por otra parte, es destacable que los trabajos de los "estudiantes-ocupados" estén vinculados al ámbito familiar; y, sin duda en algunos casos, las tareas domésticas pesan fuertemente en la vida cotidiana de las estudiantes. La opinión de estos estudiantes se centra en que la escasa compatibilidad con las tareas escolares depende del tiempo que les demanda el trabajo, y en este sentido las ofertas laborales disponibles parecen acarrear un ritmo que dificulta la combinación entre ambos roles "estudiante/trabajador".

Finalmente, lo que además se advierte en base a los fragmentos, es una mirada cargada de escepticismo y escasas posibilidades a futuro, respecto a otros jóvenes actuales. Visión que pone en primer plano y acentúa los efectos de la expansión de las adicciones, y las actividades delictivas. Llamativamente estas afirmaciones, como enunciamos en la introducción de este texto, no permanecen ajenas a los enfoques que circulan en nuestras sociedades sobre "la juventud" actual, desde una perspectiva sobre todo adulto céntrica, que parece tener cabida también en las opiniones que expresan parte de los estudiantes entrevistados, al comentar la situación de "otros" jóvenes de su misma generación.

\section{Reflexiones finales}

En la introducción señalamos que en nuestro país la política que propicia la obligatoriedad de la educación secundaria es uno de los desafíos más importantes en relación a las condiciones de vida de los jóvenes. En esta dirección, argumentamos que existe una fuerte tendencia en la opinión pública que sostiene que la juventud debe permanecer en el sistema educativo hasta concluir el ciclo secundario y sólo posteriormente integrarse a la actividad laboral. 
La señalada tendencia se presenta en el contexto de fuerte avance de la legislación proteccionista de la juventud. Legislación que, sin embargo, no termina de institucionalizarse en todo su potencial, a raíz de una serie de problemáticas vinculadas a lo que definimos como la nueva cuestión social. Así, las cosas, al tiempo que se ha promulgado una ley que ampara los derechos establecidos por la Convención de los Derechos del Niño ${ }^{8}$ y se han elevado los niveles de obligatoriedad educativa, desde algunos sectores se reclaman sanciones que tiendan al disciplinamiento y el control de los y las jóvenes, a través de medidas que muchas veces cuestionan los elementos básicos de la legislación protectiva. Parte de dicha contradicción (entre protección y disciplinamiento), se expresa en los hechos concretos, a través del acceso diferencial al diploma de la educación secundaria por parte de hombres y mujeres de distintos sectores sociales, y atraviesa también el complejo vínculo entre la educación y el trabajo.

Es en este marco que nos propusimos abordar la expresión de distintas formas de desigualdad que se manifiestan en relación a la educación de los y las jóvenes. Nos interesó, sobre todo, resaltar la disponibilidad diferencial de los estudiantes en relación al tiempo de dedicación a la actividad escolar; enfatizando la desigual carga de las responsabilidades y de las obligaciones domésticas y laborales a las que se ven expuestos estudiantes secundarios de distintos sectores sociales. Al respecto, pudimos observar que los estudiantes de sectores económicos de altos ingresos experimentan menores obligaciones laborales $y$ domésticas, y que en el caso de desarrollar alguna de estas

\footnotetext{
8 Según el comité de seguimiento, la Ley 26.061 de Protección Integral de los Derechos de Niños, Niñas y Adolescentes (promulgada el 26 de octubre de 2005) crea un sistema de protección de los derechos de todos los niños, niñas y adolescentes del país, en cuya base se encuentra el conjunto de políticas públicas básicas y universales para el pleno desarrollo de los chicos en todas las áreas: educación, salud, cultura, recreación, participación ciudadana, etc.; y define las responsabilidades de la familia, la sociedad y el Estado en relación a esos derechos, ver http://www.casacidn.org.ar/leer.php/96.
} 
ocupaciones, lo hacen en un contexto de mayor flexibilidad que les permite alternar o discontinuar sin mayores perjuicios. Por el contrario, entre los y las jóvenes de los sectores sociales de menor poder económico la obligatoriedad que alcanzan dichas actividades es central. Es decir que deben continuar con sus labores a pesar de las dificultades que les puedan ocasionar en los estudios. Así, comprobamos que en este último grupo las trayectorias educativas con sobresaltos se presentan con mayor frecuencia, acentuándose entre aquellos que desarrollan tareas intensas de forma cotidiana.

En lo que respecta a las ocupaciones concretas, hallamos que son las mujeres quienes preponderantemente se encargan de tareas propias del ámbito doméstico. La asociación directa de las mismas con las actividades domésticas sigue siendo un rasgo característico de la distribución de ocupaciones de acuerdo al género. Sin embargo, aquí también la influencia del sector social es notoria, dado que son aquellas de sectores bajos quienes asumen más intensamente este tipo de responsabilidades.

En este sentido, la continuidad en lo que podemos denominar como comportamientos asociados a "patrones tradicionales de género", nos obliga a re-pensar la asociación directa que se postula en la economía de la educación (de orientación neo-clásica) sobre el nivel educativo y la participación laboral (Becker, 1975). Frente a esta perspectiva, en cambio, consideramos que el vínculo entre el nivel educativo y la participación laboral está mediatizado por factores culturales y sociales asociados con el hogar de origen de los y las jóvenes, es decir con la efectiva distribución de oportunidades y accesos entre los distintos grupos sociales. De tal forma que la educación no es un "hecho aislado", sino que se produce en el marco de un conjunto de relaciones sociales, culturales, de género, las cuales intervienen en la acción educativa y en sus efectos posteriores (Filmus, Kaplan, Miranday Moragues, 2001).

Asimismo, la continuidad observada en las tendencias diferenciales entre hombres y mujeres nos llevó a preguntarnos: 
¿cuánto hay de nuevo y cuánto de reproducción de viejas estructuras sociales en las tendencias observadas? En referencia a este aspecto, sobre finales de los años setenta $\mathrm{P}$. Willis señaló que los jóvenes hombres de clase obrera no eran "víctimas" del fracaso escolar, sino actores que se expresaban oponiéndose a la autoridad escolar, en dirección a la afirmación de su masculinidad. La hipótesis sostenía que dicho comportamiento - asociado a la participación en ámbitos productivos - reproducía al mismo tiempo la superioridad de género (masculino) y la estructura de clases al interior del sistema capitalista (Wills, 1988).

Frente a las afirmaciones de Willis, consideramos que lo particular de esta nueva época es que la asociación de los jóvenes hombres con la actividad laboral se presenta hoy en el marco de un deterioro generalizado del mercado laboral (Aronowitz, 2004), paralelamente a un fuerte proceso de polarización social, que restringe las posibilidades de bienestar entre los grupos sociales de menores ingresos y capital educativo, signando los tránsitos entre la educación y el empleo entre los y las jóvenes contemporáneos.

Los resultados de la investigación nos desafían a pensar sobre los ambiguos matices de la desigualdad y su vínculo con aspectos educativos, generacionales y de género. Enfrentándonos con la complejidad que adquiere el diseño y la implementación de acciones tendientes a la generación de oportunidades educativas y laborales entre la juventud en nuestros días.

\section{Referencias bibliográficas}

ARONOwITZ, S. Foreword. In: Dolby, N. and DimitriAdIS, G. (eds). Learning to Labor in New Times. NY, RoultledgeFalmer, 2004.

BECKER, G. Teoría económica. México, Fondo de Cultura Económica, 1975.

BINSTOCK, G. y CERRUTTI, M. Carreras Truncadas: el abandono escolar en el nivel medio en la Argentina. Buenos Aires, UNICEF, 2005. 
Escolarización secundaria

BRASLAVSKY, C. y FILMUS, D. Último año de colegio secundario y discriminación educativa. Buenos Aires, Documentos e Informes de Investigación nº 50, FLACSO/Argentina, 1987.

DE IBARROLA, M. Paradojas recientes de la educación frente al trabajo y la inserción social. Buenos Aires, RedEtis, 2004.

Filmus, D.; KaPlan, C.; Miranda, A. y Moragues, M. Cada vez más necesaria. Cada vez más insuficiente, la escuela media en epocas de globalización. Buenos Aires, Editorial Santillana, 2001.

GALLART, M. A. Educación y empleo en mujeres de sectores populares. Revista Propuesta Educativa, año 4, n7, 1992, pp.63-67.

La evolución de la educación secundaria 1916-1970: El crecimiento cuantitativo de la matrícula y su impacto en la fuerza de trabajo (segunda parte). Revista CIAS XXXIII, n 33:1, 1984, pp.4-20.

GAMBA, S. B. (coord.) Diccionario de género y feminismos. Buenos Aires, Editorial Biblos, 2007.

JACINTO, C. La escuela media: reflexiones sobre la agenda de inclusión con calidad. Buenos Aires, Fundación Santillana, 2006.

WILLS, P. Aprendiendo a trabajar: cómo los chicos de clase obrera consiguen trabajos de clase obrera. Madrid, Akal, 1988. 